\title{
BONY INJURIES IN TRAUMA PATIENTS DIAGNOSED BY RADIOLOGICAL EXAMINATION
}

\author{
G. AMPONSAH ${ }^{1}$ and P. N. GORLEKU ${ }^{2}$ \\ ${ }^{1}$ Department of Anaesthesia \& Pain Management and ${ }^{2}$ Department of Medical Imaging, University of Cape \\ Coast, School of Medical Sciences, Cape Coast, Ghana
}

DOI: http://dx.doi.org/10.4314/gmj.v49i2.6

Corresponding Author: Professor Gladys Amponsah

Email: g.amponsah@uccsms.edu.gh

Conflict of interest: None declared

\section{SUMMARY}

Objective: This study was carried out to determine the incidence of bony injuries in trauma patients who had plain radiographs done at the Central Regional Hospital in Cape Coast.

Design: This is a retrospective study based on plain radiographs taken by trauma patients who reported to the Central Regional Hospital.

Method: The case notes of all patients with a discharge diagnosis of Road Traffic Accident or trauma of all aetiologies that presented to the hospital between January 2005 and December 2011 were retrieved, and those patients that had skeletal radiographic examinations were included in this study.

Results: The total number of cases seen was 1,133 . The ages of the patients ranged between 1 and 72 years. Sixty-nine $(6.1 \%)$ of the patients were between 1 and 4 years old, with the majority between 20 and 49 years old, constituting $52.3 \%$, with patients 60 years and above at $9.2 \%$. There was statistically significant difference between male and female patients $(p=0.001) . \quad A$ total of $912(80.5 \%)$ patients had radiographic examination done out of which only 324 (35.5\%) radiographs could be retrieved. There were $106(32.7 \%)$ radiographs with various bony injuries which was statistically significant $(p=0.001)$. Rib fractures represented $19 / 106(17.9 \%)$ of which $62.5 \%$ had multiple rib fractures. Fifty-eight (54.7\%) had long bone fractures. Other anatomical sites included the pelvis and the skull.

Conclusion: Trauma is a major public health problem in the country, involving mainly the productive age group. Unnecessary exposure to X-rays is common. Inadequate management of trauma patients negatively impacts on the outcome of trauma patients. Trauma prevention is the best way forward.

Keywords: trauma, road traffic accident, bony injuries, radiological investigations

\section{INTRODUCTION}

At birth, a newborn baby has over 300 bones, whereas on average an adult human has 206 bones. ${ }^{1}$ The number of bones can vary slightly from one individual to the other. There are about 126 bones in the hands and feet alone. ${ }^{2}$ Trauma may result in a fracture, a dislocation or both of any of these bones. Some fractures and dislocations are much more common than others, but the rarer ones are no less important to the patients who sustain them.

Although there are many causes of trauma such as industrial or sports accidents, Road Traffic Accident (RTA) remains the most frequent cause of trauma and hence bony injuries in Ghana. Available statistics indicate that there were 13,572 road traffic accidents recorded in Ghana in 2011, with 13,272 people sustaining various kinds of injuries. ${ }^{3}$

A large percentage of these victims will report to various health facilities in the country. Because the majority of these facilities are not manned by the requisite manpower, radiographs are requested for some of these patients even before they are thoroughly examined. ${ }^{4}$ Some of these requests are made in spite of the absence of X-ray machines in some of these health facilities and the constant shortages of consumables in those which have them. The number of negative radiographs may be high. This leads to poor use of scarce consumables. X-rays are used for the detection of fractures and other pathology of bones due to the very high roentgenological density of bone.

This study was therefore carried out to find out the incidence of bony injuries in trauma patients who had plain radiographs done on reporting to the Central Regional Hospital in Cape Coast. 


\section{PATIENTS AND METHODS}

This was a retrospective study, which took place at the Central Regional Hospital, Cape Coast. All cases with a discharge diagnosis of RTA or trauma of all aetiologies that presented to the hospital between January 2005 and December 2011 were retrieved, and those patients that had undergone skeletal radiographic examinations were included in this study. Information was obtained from the admission and discharge book of the Accident and Emergency (A and E) department as well as the records of the X-ray department of the hospital.

No previous reports have been made on the radiographs. The radiographs were reviewed by a Radiologist and compared to the final diagnosis upon discharge. The anticipated bony injury was not found in most of the radiographs reviewed.

The data was entered using SPSS version 16 software. The data was analyzed using frequencies, percentages and Chi-square where appropriate. A p value of $<0.05$ was considered statistically significant.

\section{RESULTS}

The total number of trauma cases seen within the period was 1,133 . The ages of the patients ranged between 1 and 72 years. A total of $69(6.1 \%)$ of the patients were between the ages of 1-4 years. The majority of the trauma patients were between the ages of 20-34 and 35-49 age groups. The two groups constituted 593(52.3\%) of the entire age groupings. Patients of 60 years and above totalled only $104(9.2 \%)$ (Table 1).

Table 1 Age distribution of all the trauma patients

\begin{tabular}{|l|l|l|l|l|l|l|l|}
\hline YEAR & $\mathbf{1 - 9}$ & $\mathbf{1 0 - 1 9}$ & $\mathbf{2 0 - 3 4}$ & $\mathbf{3 5 - 4 9}$ & $\mathbf{5 0 - 5 9}$ & $\begin{array}{c}\text { Above } \\
\mathbf{6 0}\end{array}$ & Total \\
\hline 2005 & 22 & 23 & 16 & 36 & 19 & 27 & 143 \\
\hline 2006 & 20 & 47 & 27 & 45 & 16 & 30 & 185 \\
\hline 2007 & 39 & 13 & 53 & 41 & 20 & 10 & 176 \\
\hline 2008 & 12 & 31 & 63 & 66 & 28 & 9 & 209 \\
\hline 2009 & 16 & 46 & 76 & 59 & 21 & 15 & 233 \\
\hline 2010 & 23 & 7 & 30 & 14 & 5 & 5 & 84 \\
\hline 2011 & 11 & 5 & 42 & 25 & 12 & 8 & 103 \\
\hline TOTAL & 143 & 172 & 307 & 286 & 121 & 104 & 1133 \\
& $(12.6 \%)$ & $(15.2 \%)$ & $(27.1)$ & $(25.2 \%)$ & $(10.7 \%)$ & $(9.2 \%)$ & \\
& & & & & & \\
\hline
\end{tabular}

There were $755(66.6 \%)$ males and 378 (33.4\%) females giving a ratio of 2:1. (Figure 1) There was statistical difference between male and female patients. $(\mathrm{p}=0.001)$. The year-to-year comparison of the trauma patients was not significant with a $\mathrm{p}$ value of 0.155 .
Based on the classification used at the hospital's Accident and Emergency Unit, all the patients were grouped into three: (i) trauma with serious injuries, (ii) lacerations and abrasions secondary to RTA and (iii) traumatic amputations. There were $82(7.2 \%)$ cases of traumatic amputations within the period, with 30 $(36.6 \%)$ of the cases being recorded in 2010 alone. Serious injuries included visceral injuries in addition to the skeletal fractures.

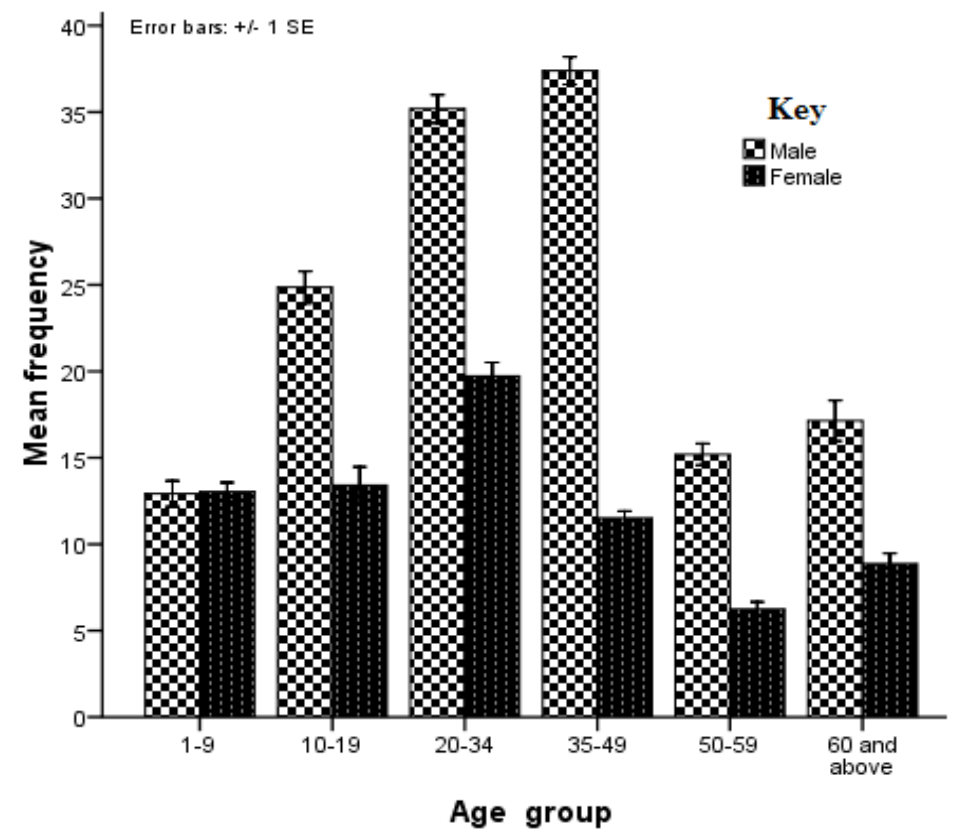

Figure 1 Bar graph showing age and sex distribution of the patients

Table 2 Anatomical distribution of fractures

\begin{tabular}{|l|l|l|}
\hline Anatomical site & No. of patients & Percentage (\%) \\
\hline Ribs & 19 & 17.9 \\
\hline Tibia & 15 & 14.2 \\
\hline Radius & 11 & 10.4 \\
\hline Clavicle & 10 & 9.4 \\
\hline Ulna & 9 & 8.5 \\
\hline Humerus & 9 & 8.5 \\
\hline Metaphyses & 8 & 7.5 \\
\hline Fibula & 8 & 7.5 \\
\hline Skull & 7 & 6.6 \\
\hline Femur & 6 & 5.7 \\
\hline Pelvis & 4 & 3.8 \\
\hline Total & 106 & 100.0 \\
\hline
\end{tabular}

A total of $912(80.5 \%)$ patients had radiographic examination done. As a result of very poor archiving, it was possible to retrieve and review only $324(35.6 \%)$ radiographs. Of all the radiographs reviewed, there were $106(32.7 \%)$ with various bony injuries, which was statistically significant (Chi-square $=38.716$, df- 1 , $\mathrm{p}=0.001$ ). The anatomical distribution of the fractures is shown in Table 2. 
Rib fractures represented 19/106 (17.9\%) of which $62.5 \%$ had multiple rib fractures. Fifty-eight (54.7\%) of the patients had long bone fractures.

\section{DISCUSSION}

The Accident and Emergency Unit of the Central Regional Hospital in Cape Coast is the only facility, which receives trauma patients in the Metropolis.

The Unit is manned by medical officers and house officers who do not have much experience in the initial management of trauma patients. This may partly account for the high percentage $(80.5 \%)$ of patients who had radiographs done. With regards to radiological investigations in trauma patients, we must be guided that, a useful investigation is that in which the results either positive or negative, will alter the management or add confidence to the clinician's diagnosis. One is more likely to make a mistake because a patient was not examined than because a radiograph was not taken.

The poor record keeping and storage of patient data in the hospital, a situation that is seen in most hospitals in the country, resulted in the retrieval of only 324 (35.6\%) out of the 912 radiographs taken. This poor record keeping in our health facilities has led to the situation whereby some patients take their film jackets home for fear of losing them. This may also contribute to the low retrieval rate. The hospital has now embarked on electronic record keeping to mitigate against this practice.

Out of the number of retrieved radiographs, only about one third had bony injuries. A large proportion of the patients were therefore exposed to unnecessary ionizing radiation. The financial implication to the patient together with the wrong use of the scarce consumables is also noteworthy. Some of the health facilities may not have an X-ray machine which is in working condition or the consumables may not be available. Since most health facilities do not have an ambulance, it means that the patients may have to travel to the nearest health facility where X-rays are available on public transport, thus incurring additional cost.

Some fractures especially those of the long bones, can be diagnosed clinically using signs like deformity, tenderness and loss of function. ${ }^{5}$ However radiographs can be used to determine the precise nature of the injury. Long bone fractures comprised 58 (54.7\%) of all the fractures. In addition, radiographic examinations are indicated in the following situations: injuries of the ankle, elbow, hip or any long bone fracture where there might be a dislocation at the upper end and severe foot injuries where the patient cannot walk. ${ }^{6}$
A common mistake in the request for radiographic examination on patients is that enough of the patient's limb is sometimes not X-rayed. It is advised that in all long bone injuries, the radiographs taken must include the joints above and below the fracture in order not to miss any proximal or distal injuries. ${ }^{7}$

Long bone fractures can lead to complications such as non-union, malunion, shortening and deformity. Some patients have chronic pain as a result of the fractures. The complication of long bone fractures is made worse because some of the patients seek help from herbalists and traditional bonesetters after the diagnosis has been made. They sometimes come back to the hospitals when very serious complications like infections have set in, resulting in limbs sometimes being amputated.

The significant difference between male and female trauma patients (ratio of 2:1) is a reflection of the fact that more males are involved in economic activities, which include travelling within and outside their places of abode. Motor vehicles are the main means of transport in Ghana.

The poor maintenance culture of vehicles, over speeding by drivers, bad attitude by drivers and sometimes even passengers, have led to many deaths on our roads each year. The Accra-Cape CoastTakoradi road is one of the busiest roads in Ghana and noted for the large number of road traffic accidents annually. Over 30 people lost their lives within 2 weeks at the beginning of 2013 on this road. This is in addition to those who sustained injuries including bony injuries. A newly constructed road with speed ramps has not stopped drivers from over speeding. Some even drive at top speed when driving through towns and villages.

Road traffic accidents are the main cause of trauma in Ghana. Other causes of trauma such as domestic, industrial, assaults and civil unrest are currently lower. ${ }^{8}$ With the oil and gas industry just starting, Ghana hopes to industrialize. Industrial accidents are likely to go up. A new Trauma Hospital, the first of its kind in Ghana has been built in Winneba in the Central Region. This is to cater for the increasing number of trauma patients expected with the oil and gas industry as a lot of the machinery and personnel for the industry will be on vehicles using the Accra-Cape Coast road on their way to the Western Region of the country. Currently, most of the oil and gas find is located in the Western Region of Ghana. 
A total of 69 patients $(6.1 \%)$ were between the ages of 1 and 4 years. Some of these patients might have been passengers on the vehicles that were involved in the accidents. There was not enough data to ascertain whether some of these cases might have been due to Non Accidental Trauma (child abuse).

The study also showed that $593(52.3 \%)$ of the patients were between the ages 20-49 years. This is the most productive working-age group in the country. Even though this study did not include the management of injuries and outcomes, reports from other hospitals in the country demonstrate the socio-economic implication of trauma especially in those who sustain bony injuries. In one of such report from Korle $\mathrm{Bu}$ Teaching Hospital, carried by TV 3 in 2012, one of the patients had been on admission for 6 months and he did not know when he was going to be discharged.

Any patient who sustains a bony injury, no matter how minor, will be incapacitated for a period ranging from a few weeks to months. In some instances, there is permanent disability, which may be associated with chronic pain. This means that some of these patients can never go back to their previous source of income.

Eighty-two (7.2\%) of the patients had traumatic amputation as a result of their injuries. Amputations following trauma or surgical intervention result in severe economic hardship. Most of the patients cannot afford the cost of artificial limbs. Another problem facing the patient is the limitation in accessibility as the Ministry of Health has only one Limb Fitting Centre for the whole country, which is based in Accra. The centre has not seen any major upgrading in its equipment or personnel since it was established over 50 years ago. Some mission hospitals have similar facilities but these are still not enough. A number of these amputees are seen begging in the streets.

The anatomical site of bony injuries has a bearing on the morbidity and mortality of the patient. Some of the patients may die from the primary injury or from the secondary complications, as seen for example, following fractures of the ribs and the skull. ${ }^{9}$

Ribs and clavicles are the most common broken bones in the human body following trauma. ${ }^{10}$ The two sites made up between them a total of $27.3 \%$ of all the fractures observed (Table 2). Fracture of the clavicle is common, and is often fractured in the middle third of its length which is its weakest point.
Rib fractures alone, which was the most common bone fractured and occurred in $17.9 \%$ (Table 2) of all the patients, can lead to severe pain, difficulty in breathing, flail chest, hypoxia and hypercarbia depending on the number of ribs involved and whether the fractures are on one or both sides of the thoracic cage. Patients with three or more rib fractures have a greater likelihood of hepatic and splenic injury, resulting in a higher mortality rate, a higher injury severity score (ISS) and longer intensive care and hospital stays than those with fewer rib fractures. ${ }^{11}$ The patient can also develop a simple or even a tension pneumothorax as a complication of rib fractures. Adequate pain relief, using available analgesics such as pethidine or morphine at an appropriate dose and frequency, is required to prevent further complications. In one study, the use of thoracic epidural provided better analgesia than patient controlled analgesia. ${ }^{12}$ These methods of pain relief are currently not available in most hospitals.

Metaphyseal fractures which constituted $7.5 \%$ of all the bony injuries in the study usually occur in children. If these are not properly managed from the onset they can result in serious complications like limb shortening. These patients should be referred early to orthopaedic specialists for proper management. ${ }^{13}$

The outcome of skull fractures $(6.6 \%$ of all the cases) depends on the extent of the damage of underlying brain tissue. Brain involvement can lead to permanent disabilities of varying degrees. The head injury can be made worse by hypoxia, hypercarbia and hypotension. These complications should be avoided or treated promptly if they occur, to minimize secondary damage. There are a few neurosurgeons in Ghana based in 2 or 3 centres only. Most patients who sustain head injuries are therefore managed by general-duty physicians in the initial stages. They are referred to the specialists when irreversible damage has occurred in the patients. A number of these patients end up with various degrees of permanent neurological deficits. The economic implications to the family and society cannot be easily quantified.

Fracture of the pelvis occurred in $3.8 \%$ of the patients. Pelvic fractures can lead to other serious complications depending on the extent of the disruption of the bony cage. Common associated injuries include injury of the urethra, corpora carvenosa (penis), the bladder and the bladder neck. Urethra injury can lead to stricture, incontinence and impotence. ${ }^{14}$ Patients who develop urethra stricture face a long waiting list and a series of reconstructive surgeries. 


\section{CONCLUSION}

This study shows that trauma is a major public health problem in the country. This involves mainly the productive age group, as seen in this study where $52.3 \%$ of patients were between the ages of 20 and 49 . Many patients are exposed to ionizing radiation because of unnecessary requests for radiographs but bony injuries are not seen in the majority of the patients. Even though many die as result of trauma, many more survive their injuries. The outcome of trauma can lead to loss of income, chronic disabilities including pain. Trauma prevention therefore is the best way forward.

\section{RECOMMENDATIONS}

Trauma prevention is the single most important aspect of trauma care management. All efforts must be channelled towards educating patients about effective ways of preventing injury. Some of the preventive strategies include improvements in road safety education, better driver training, preventing drivers from drinking alcohol, pedestrian and cyclist awareness, wearing of seat belts in cars or helmets for motor cyclists and limiting civil and urban unrest. There is the need to train health personnel and adequately equip health facilities to provide basic trauma care to all patients.

\section{ACKNOWLEDGEMENT}

The authors are grateful to Prof Donald Nzeh for reviewing the manuscript for us before submission.

\section{REFERENCES}

1. Lindsay DT. Functional Human Anatomy. $1^{\text {st }}$ Ed. Georgia: Mosby, 1996. P 115-120

2. Gunstream SE. Anatomy and Physiology with integrated study guide. $2^{\text {nd }}$ Ed.Boston: McGraw Hill, 2000. P 96- 106.

3. Road accidents on the rise with 2,330 lives lost in 2011. Ghana News Agency Publication $30^{\text {th }}$ Jan. 2012

4. Antwi-Bosiako Y. Human Resource for HealthPolicies and Strategies 2007-2011. Available at: http://www.ghanahealthserivice.org. Accessed on 8th May 2014

5. King M, Bewes P, "Primary Surgery" (2)-Trauma: Varieties of Bony injury: X-ray of Bony injuries. Updated/Addition May, 2008. Ch.69: 2-8.

Available at: http:/www.primarysurgery.org/ps/vol2/html/index.html Accessed 13th February 2011.

6. King M, Bewes P. Primary Surgery (2)-Trauma: Broken Bones.Ch. 69.2. Updated/Addition May, 2008. Available at: http://www.primary surgery.org/ps/vol2/html/index.html. Accessed 10th February 2011.

7. Stoller D, Tirman P. Diagnostic ImagingMusculoskeletal. 1st Ed. Salt Lake City: WB Saunders 2002; P12-17.

8. Surgical Care at the District Hospital. Trauma in Perspective. World Health Organization manual. 2003. P 372-374.

9. Ziegler DW, Agarwal NN. The morbidity and mortality of rib fractures. J Trauma 1994; 37:975 $-9$

10. Khan LA, Bradnock TJ, Scott C, Robinson CM. Fractures of the Clavicle. J Bone Joint Surg Am 2009; 91(2): 447-60.

11. Lee RB, Bass SM, Morris JA. 'Three or more rib fractures as an indicator for transfer to a level 1 trauma centre: a population-based study. J Trauma 1990; 30:689.

12. Wu CL, Jani ND, Perkins FM, Barquist E. Thoracic Epidural Analgesia versus Intravenous Patient- Controlled Analgesia for the Treatment of Rib Fracture Pain after Motor vehicle Crash. Journal of Trauma- Injury Infection \& Critical Care 1999; 47 (3): 564-567.

13. King M., Bewes P. Primary Surgery (2) -Trauma: Fractures in Children: Epiphyseal Injuries in children. Updated/Addition May, 2008. Ch. 69.9 10.Available at: http:/www.primarysurgery.org/ps/vol2/html/index.html. Accessed 24th February 2011.

14. Brandes S, Borrelli J. Pelvic fracture and associated urologic injuries. World J Surg 2001; 25 (12): 1578 - 1587 